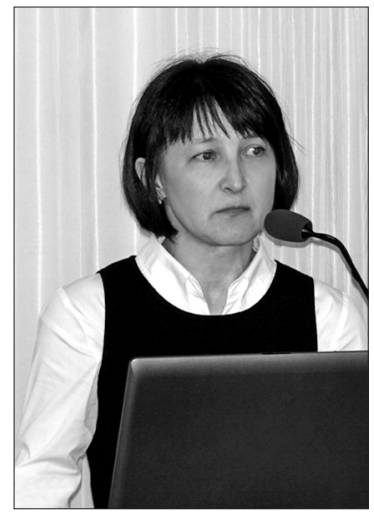

\title{
Tatiana Misijuk
}

\section{IKONOSTAS}

Słowa kluczowe: ikona, ikonostas, sztuka sakralna, symbol, kanon ikonografii, historia sztuki, liturgia

Mówiąc o ikonostasie powinniśmy rozpatrywać go dwupłaszczyznowo:

- jako szczególne miejsce w świątyni - to swego rodzaju granica;

- jako formę plastyczną - całe bogactwo środków artystycznych: kompozycja, forma, konstrukcja, materiał, rzeźba, kolor, światło, faktura etc.,

- przy czym obie te płaszczyzny przenikają się, ale pierwsza jest zawsze przyczynowa, a druga wynikowa.

\section{IKONOSTAS JAKO MIEJSCE W ŚWIĄTYNI}

Świątynia to miejsce naszego wstępowania do nieba. Wchodząc do świątyni, w przestrzeni ziemskiej pokonujemy określone odległości: przedsionek (gr. narteks, cs. pritwor), nawę, ikonostas, sanktuarium, stół ołtarza (cs. prestoł), antimension, kielich z Najświętszym Sakramentem - tak zmierzamy do Boga. Ruch liturgiczny to ruch wewnętrzny wprowadzający nas w głębię innego - duchowego 
wymiaru. Sanktuarium jest miejscem należącym do świata niewidzialnego. Symboliczne objaśnienia przestrzeni świątyni przypisują sanktuarium różne znaczenia, ale zawsze wyodrębniają je jako miejsce szczególne, niepojęte, transcendentne, postrzegają je jako element świata Boskiego w świecie widzialnym, jako duszę człowieka w ciele, misterium Świętej Trójcy w świątyni jako miejscu jej działania.

Mnogość interpretacji potęguje ontologiczne znaczenie sanktuarium jako symbolu świata niewidzialnego. To, co niewidzialne jest niedostępne dla naszej percepcji wzrokowej (zmysłowej). Na granicy nieba i ziemi stoją świadkowie obu tych sfer świata - święci. To poprzez nich niewidzialne, staje się bliskie i dostępne. To z tych „żywych kamieni” zbudowany jest ikonostas - ściana rozdzielająca i łącząca jednocześnie dwie rzeczywistości - Boską, wieczną i ludzką, tymczasową. Otwierają się okna na inną rzeczywistość której głębia to nie to co fizycznie jest za materialną ścianą ikonostasu, lecz czwarty wymiar - głębia duchowa.

Pierwotna forma ikonostasu to niska kolumnada ustawiona pomiędzy częścią ołtarzową a nawą świątyni. Z czasem na wieńczącym kolumny architrawie pojawiły się ikony. Gdy kolumnada była wyższa, ikony umieszczone zostały pod architrawem, pomiędzy kolumnami. Z czasem pojawiły się wypełnione ikonami kolejne piętra ikonostasu. Choć nie pełnią już swej pierwotnej funkcji, kolumny, półkolumny, pilastry zawsze były i ciągle są charakterystycznym elementem składowym ikonostasu, jako część jego dekoracji.

Aż do końca IV w. rozmiary ikonostasu nie przeszkadzały wiernym w pełnym uczestnictwie w misterium św. Liturgii, celebrowanej w ołtarzu. Paul Evdokimov stwierdził, iż do rozrastania się tej przegrody doprowadziły względy dydaktyczne, pragnienie ikonograficznego unaocznienia wiernym ekonomii zbawienia. Zagroziło to jednak czynnemu udziałowi wiernych w działaniach liturgicznych. W Rosji tradycja Józefa Wołokołamskiego, promująca wspaniałość i bogactwo zdobnictwa obrzędowego, przezwyciężyła duchową prostotę i umiar Nila Sorskiego. Zdaniem Evdokimova spowodowało to pojawienie się pomiędzy kapłanem a ludem napięcia, istniejącego po- 
między Kościołem i światem, a wraz z nim niebezpieczeństwo zbyt silnego rozdziału pomiędzy sanktuarium a nawą.

Warto w tym miejscu zauważyć, iż w historii Cerkwi rozrost ikonostasu, realizm w ikonie, nadmierna dekoracyjność, przerost formy nad treścią w architekturze, ikonografii i śpiewie liturgicznym związane były z osłabieniem życia duchowego i niezgodnymi z wcześniejszą tradycją wpływami z zewnątrz.

Obecnie w wielu lokalnych Cerkwiach prawosławnych zarysowuje się narastająca tendencja do powrotu do dawnej prostoty i oszczędności form w każdej z tych dziedzin, co pozwala wiernym słyszeć modlitwy kanonu eucharystycznego i pełniej uczestniczyć w misterium św. Liturgii.

\section{IKONOSTAS JAKO FORMA PRZESTRZENNA}

Jako forma przestrzenna ikonostas w swej w najprostszej wersji może stanowić kompozycję składającą się z ikon Bogarodzicy z Dzieciątkiem (Wcielenie - pierwsze przyjście Chrystusa), rajskich czy królewskiej bramy oraz ikony Paruzji - powtórnego przyjścia Chrystusa w chwale. Na skrzydłach królewskiej bramy umieszczana jest ikona Zwiastowania Bogarodzicy i czterech Ewangelistów. W ikonostasie są też drzwi diakońskie. W bardziej rozbudowanych formach ikonostasu w pierwszym jego rzędzie pojawia się ikona święta lub świętego danej cerkwi, a nad Królewską Bramą ikona Ostatniej Wieczerzy. Następny rząd stanowi zwykle kompozycja Deesis - błaganie, orędownictwo Bogarodzicy i Jana Chrzciciela, świętych i aniołów przed Chrystusem. Następne rzędy to dwanaście wielkich świąt, starotestamentowi prorocy i patriarchowie.

Technologie wykonania ikonostasu to: drewno, kamień, ceramika, metaloplastyka. Projektując formę ikonostasu należy pamiętać, iż środki plastyczne, którymi dysponuje dana technologia, powinny być dobrane w taki sposób, aby nie zdominować ikony. Bogaty światłocień rzeźby, zbyt duży kontrast kamienia, zbyt bogaty rysunek samej formy ikonostasu, niewłaściwe sztuczne oświetlenie może spowodo- 
wać, iż płaska, pozbawiona światłocienia, lecz bogata w „wymowną” symbolikę koloru ikona staje się „zakrzyczana” i zagłuszona.

Oto kilka przykładów ikonostasów w różnych przejawach ich formy.

Pierwotna forma ikonostasu to niska kolumnada ustawiona pomiędzy częścią ołtarzową a nawą świątyni.
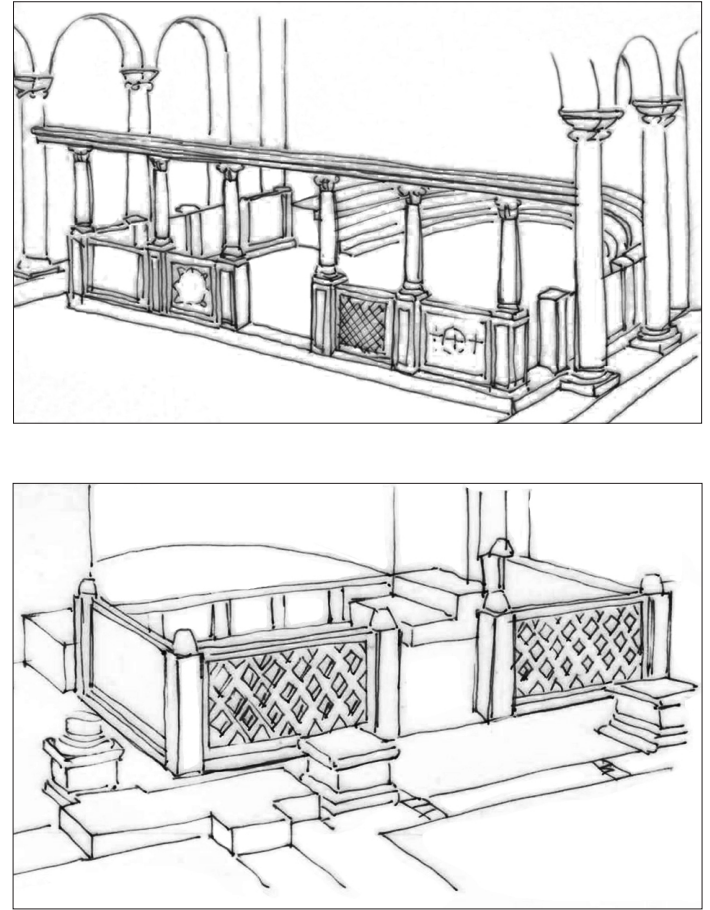

Il. 1. Bazylika „Aphentali” na wyspie Lesbos, IV w. (rys. na podstawie rekonstrukcji A. Orlandos)

Il. 2. Bazylika z IV wieku w Ochrydzie (rys. na podstawie rekonstrukcji A. Orlandos)

Forma ikonostasu, kolorystyka, dekoracja i detal służą afirmacji ikony.

Proporcje ikonostasu są bardzo harmonijnie zestawione $\mathrm{z}$ proporcjami wnętrza - wielkościami łuków, podziałami poziomymi polichromii. Naturalny kolor drewna ikonostasu współgra z żółtą ochrą tła ikon polichromii. Delikatny relief pasów dekoracji i zachowany 
Il. 3. Cerkiew św. Mikołaja we Frankfurcie

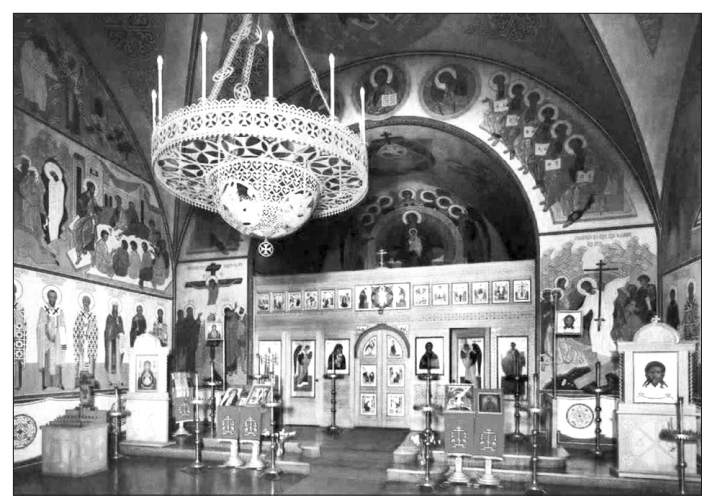

rysunek drewna to ubogacające całość elementy, których wielkość i siła oddziaływania zostały zaprojektowane w zgodzie z czytelną w tym wnętrzu zasadą afirmacji ikony.

Przykład niewysokiego ikonostasu w monumentalnym wnętrzu świątyni (il. 4). Kamienna forma dzięki kolorystyce i koronkom płaskorzeźb jest lekka, a jej rytmiczna kompozycja współgra z symetrycznym układem programu ikonograficznego części ołtarzowej.

Minimalistyczna forma ikonostasu definiuje charakter tego małego wnętrza (il. 5). Główny element - łuk Królewskiej Bramy podkreśla wertykalny charakter przestrzeni. Ikonostas, polichromia, kolorystyka wnętrza, detal, stanowią bardzo spójną całość, konsekwentnie zbudowaną przestrzeń sakralną.

Il. 4. Cerkiew św. Dymitra w Salonikach

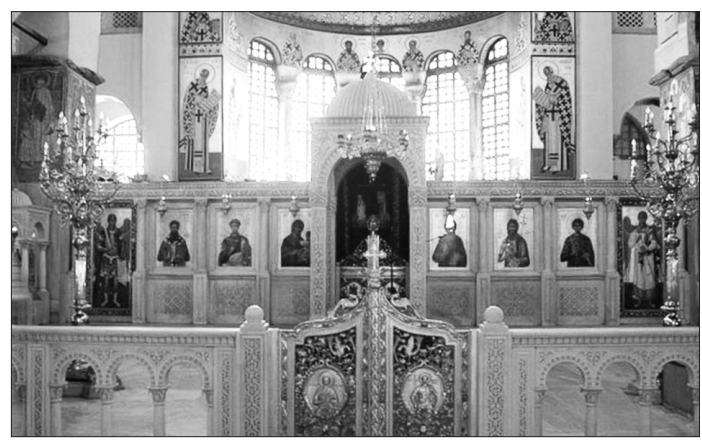




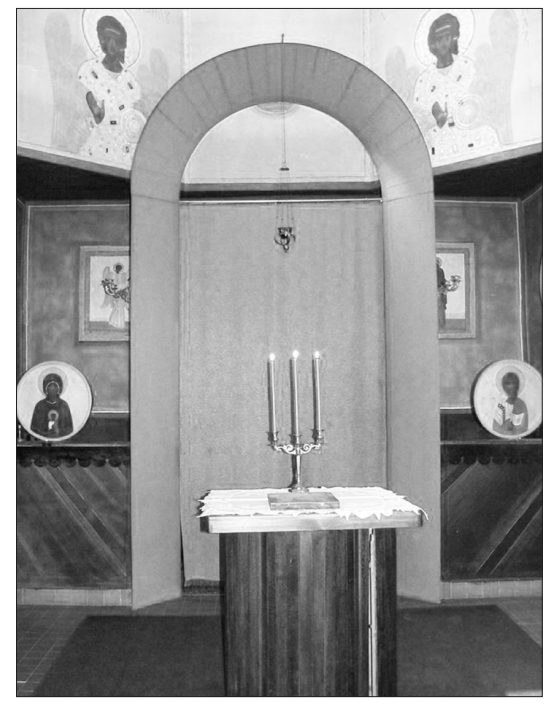

Il. 5. Baptysterium przy cerkwi św. Archanioła Michała w Bielsku Podlaskim. Projekt ikonostasu i polichromia prof. Jerzy Nowosielski

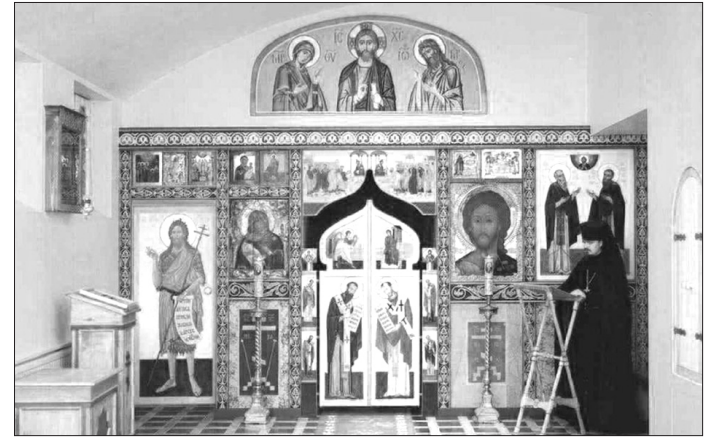

Il. 6. Uusi Valamo (Monaster Nowy Wałaam, Finlandia), kaplica św. Sergiusza i Hermana

Ikonostas w formie prostokąta od góry zamknięty prostą linią gzymsu (najczęściej górny gzyms wieńczy forma krzyża, często z tablicami Dekalogu) - il. 6. Kompozycja ikon w ikonostasie nie jest symetryczna ze względu na wymiary i styl ikon a mimo to stanowi harmonijną całość. Ważną rolę w scaleniu kompozycji mają dwa motywy dekoracyjne porządkujące różnice wielkości ikon. Całość wieńczy kompozycja Deesis w formie polichromii na ścianie. Przy tak małej a bogatej formie ikonostasu i małym wnętrzu, zadbano aby w dalszej części pojawiło się tylko kilka ikon w rytmicznym układzie. 
Il. 7. Cerkiew św. proroka Eliasza parafii św. Jana Klimaka na Woli w Warszawie

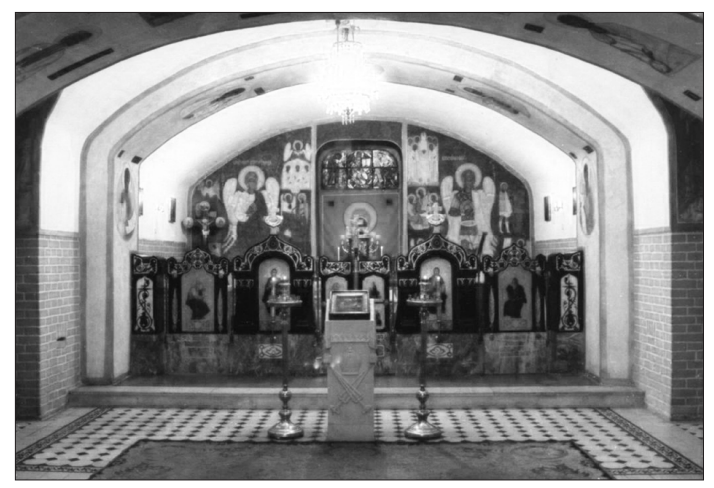

Bardzo niska historyczna forma ikonostasu zestawiona jest w tej dolnej cerkwi z polichromią profesora Jerzego Nowosielskiego. Forma wydaje się być wręcz nienaturalnie „przyciśnięta”, gdy patrzymy na proporcje przekroju pionowego wnętrza. Trafność decyzji projektowych doceniamy jednak w czasie św. Liturgii dzięki żywemu uczestnictwu w Misterium.

Zasadniczym dla koncepcji całości wnętrza jest umieszczenie kompozycji Deesis na krzyżowej formie zbudowanej na przeciwległych ścianach wnętrza, które określają centralny, dośrodkowy układ przestrzeni (mimo prostokątnego rzutu wnętrza) - il. 8, 9. Podkreśleniu tego służy również sposób oświetlenia wnętrza. Forma ikonostasu eksponuje dwie największe ikony - Bogarodzicy z Dzieciątkiem i Chrystusa. W przechodzi w formę „świecznika”, który ogniem świec i „mgłą świętych” matowego szkła prowadzi do prezbiterium. 

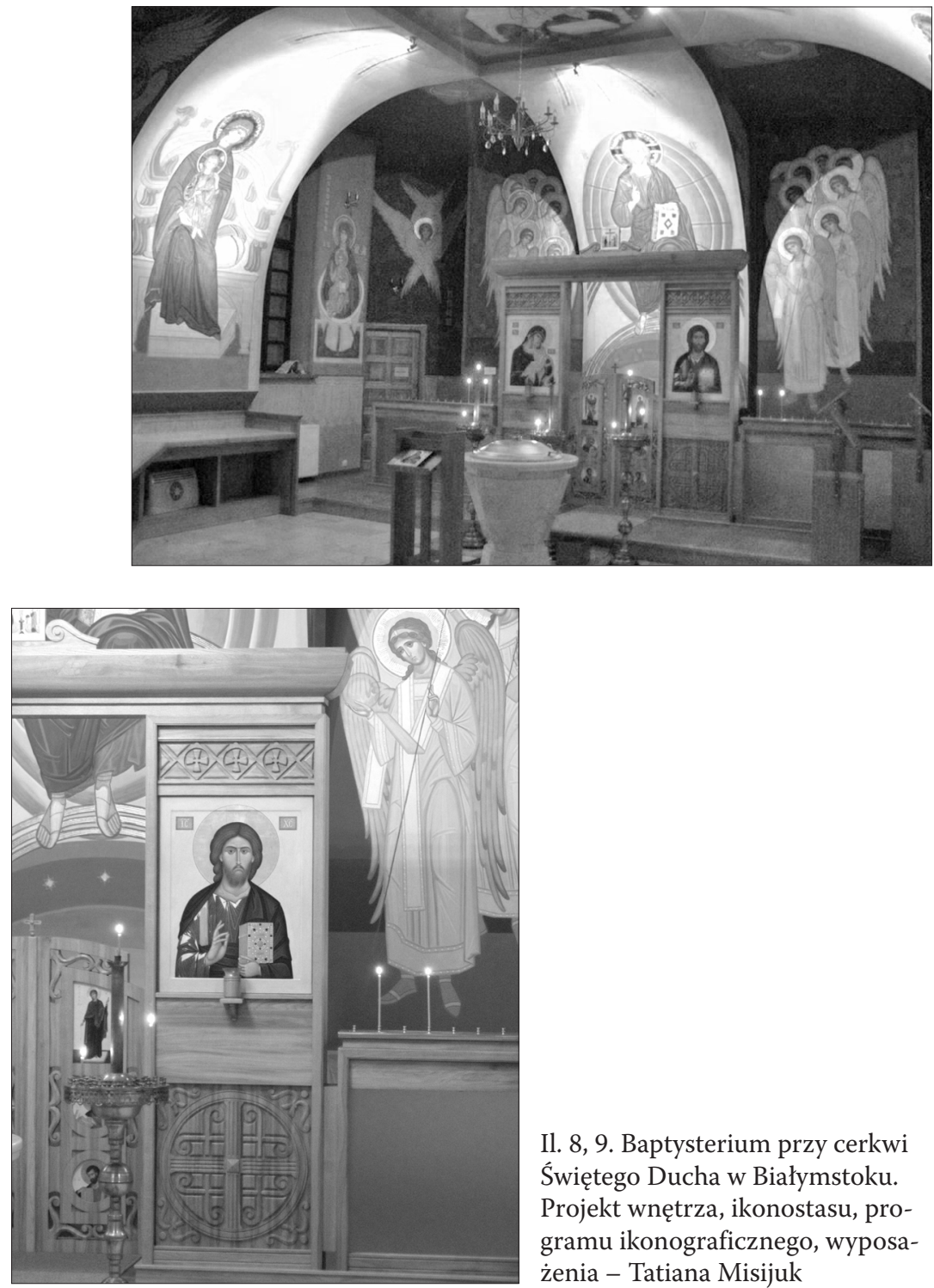

Il. 8, 9. Baptysterium przy cerkwi Świętego Ducha w Białymstoku. Projekt wnętrza, ikonostasu, programu ikonograficznego, wyposażenia - Tatiana Misijuk 


\section{SUMMARY}

Tatiana Misijuk

\section{Iconostasis}

Keywords: icon, iconostasis, sacred art, symbol, canon of iconography, history of art, liturgy

The paper indicates a complex meaning of the iconostasis both in sacred art and liturgics of the Orthodox Church. Selected examples illustrate a process of historical development of the iconostasis, contemporary variety of forms and its influence on worship celebrated in the Orthodox church. 